\title{
A synergistic interaction of 17- $\beta$-estradiol with specific cannabinoid receptor type 2 antagonist/inverse agonist on proliferation activity in primary human osteoblasts
}

\author{
MARKO HOJNIK ${ }^{1 *}$, LUKA DOBOVIŠEK $^{1^{*}}$, ŽELJKO KNEZ $^{2}$ and POLONCA FERK ${ }^{1}$ \\ ${ }^{1}$ Department of Pharmacology and Experimental Toxicology, Faculty of Medicine; \\ ${ }^{2}$ Faculty of Chemistry and Chemical Engineering, University of Maribor, Maribor SI-2000, Slovenia
}

Received September 15, 2014; Accepted March 2, 2015

DOI: $10.3892 /$ br.2015.469

\begin{abstract}
The bone remodeling process is influenced by various factors, including estrogens and transmitters of the endocannabinoid system. In osteoblasts, cannabinoid receptors 2 (CB-2) are expressed at a much higher level compared to $\mathrm{CB}-1$ receptors. Previous studies have shown that estrogens could influence $\mathrm{CB}-2$ receptor expression. In the present study, the possible interactions of a specific CB-2 agonist and a specific CB-2 antagonist/inverse agonist with 17- $\beta$-estradiol were investigated in primary human osteoblasts (HOB). HOB cells were cultured in phenol red-free osteoblast growth medium $\left(37^{\circ} \mathrm{C}, 5 \% \mathrm{CO}_{2}\right)$. In their 5 th passage, $\mathrm{HOB}$ were exposed to different concentrations of i) $17-\beta$-estradiol (1, 10 and $100 \mathrm{nM})$; ii) a specific CB-2 agonist (R,S)-AM1241 (1 and $7.5 \mu \mathrm{M})$; and iii) a specific CB-2 antagonist/inverse agonist AM630 $(10 \mu \mathrm{M})$ and to selected combinations of the substances. After 24 and $48 \mathrm{~h}$ of incubation, HOB proliferation activity was measured using a WST-8 assay. Alkaline phosphatase activity was also evaluated using spectrophotometry. Concomitant exposure of HOB to $17-\beta$-estradiol $(10 \mathrm{nM})$ and to specific CB-2 antagonist/inverse agonist $(10 \mu \mathrm{M})$ showed similar HOB proliferation activity to $\mathrm{HOB}$ incubated with $17-\beta$-estradiol only at a $100 \mathrm{nM}$ concentration. By contrast, concomitant incubation of $\mathrm{HOB}$ with 17- $\beta$-estradiol $(10 \mathrm{nM})$ and specific CB-2 agonist $(7.5 \mu \mathrm{M})$ resulted in decreased $\mathrm{HOB}$ proliferation activity as compared to HOB incubated with $17-\beta$-estradiol only (10 nM). Similar findings were observed after 24 and $48 \mathrm{~h}$ of incubation. In all the experiments, HOB successfully passed the alkaline phosphatase differentiation test. In conclusion, for the first
\end{abstract}

Correspondence to: Professor Polonca Ferk, Department of Pharmacology and Experimental Toxicology, Faculty of Medicine, University of Maribor, 8 Taborska Street, Maribor SI-2000, Slovenia E-mail: polonca.ferk@guest.arnes.si

*Contributed equally

Key words: cannabinoids, cannabinoid receptor type 2 inverse agonist, 17- $\beta$-estradiol, osteoblasts, osteoporosis time a synergistic interaction between 17- $\beta$-estradiol and specific CB-2 antagonist/inverse agonist was observed in HOB. Understanding the molecular pathways of this interaction would be of great importance in developing more efficient and safer drugs for treating or preventing bone diseases.

\section{Introduction}

Bone remodeling is the main process in maintaining the integrity of bone structure. Throughout life, bones undergo three phases: Phase of rapid skeletal growth and increasing bone mineral density, sustenance phase and phase of predominant bone resorption causing bone loss. The bone remodeling process is influenced by numerous factors, including estrogens and the endocannabinoid system. Misbalance of bone remodeling mechanisms causes one of the most common degenerative diseases in developed countries, osteoporosis (1). It is estimated that $>200$ million people worldwide suffer from osteoporosis. The costs of health care services in the European Union as consequences of osteoporotic complications are already considerable and, if current trends continue, the costs are predicted to double by 2050 (2).

Osteoblasts are influenced by estrogens at the cellular and molecular level. Estrogens bind to nuclear estrogen receptors (ERs) in osteoblasts, the ERs dimerize and act as transcription factors modulating the expression of specific DNA sequences (3). Estrogens increase collagen I and osteoprotegerin gene expression and certain evidence indicates inhibitory effects of estrogens on osteoblast apoptosis $(4,5)$.

Cannabinoids bind and activate cannabinoid receptors 1 and 2 (CB-1 and -2 receptors), as well as non-CB-1/CB-2 receptor GPR55 and vanilloid type 1 receptor (TRPV1) (6-8). CB-1 receptors are predominantly located in the central nervous system, whereas CB-2 receptors are expressed in the immune system, cirrhotic liver, arteriosclerotic plaques, gastrointestinal mucosa and during brain inflammation (9-11). CB-2 receptors have also been reported to have a significantly higher expression in osteoblasts, osteoclasts and osteocytes compared to CB-1 receptors (12-14). Therefore, specific CB-2 agonists/antagonists could be involved in the regulation of bone remodeling as a result of their effects on osteoblasts and osteoclasts. In addition, CB-2 receptor specific ligands do not 
induce psychoactive adverse effects, making them more suitable for potential clinical use (15). The $\mathrm{CB} 1$ and $\mathrm{CB} 2$ receptors inhibit adenylyl cyclase activity, which is linked to a variety of secondary messengers, including p42/44 mitogen-activated protein kinase (16-18), p38 mitogen-activated protein kinase (19), c-Jun N-terminal kinase (20), activator protein 1 and $\mathrm{Ca}^{2+}$ transients $(18,21)$. The role of GPR55 receptor in bone formation has not been extensively studied and appears to be minor (7). The TRPV1 receptor is also considered to be important in the pathogenesis of osteoporosis $(22,23)$.

Increased expression of $\mathrm{CB}-2$ receptors was found on osteoclasts when they were treated with $17-\beta$-estradiol (24). Our new hypothesis is that $17-\beta$-estradiol could also influence the $\mathrm{CB}-2$ receptor expression in osteoblasts and is based on the $17-\beta$-estradiol action on ERs and changes in gene transcription.

Accordingly, a possible interaction between 17- $\beta$-estradiol and specific CB-2 agonist and/or antagonist was considered and, to the best of our knowledge, for the first time the hypothesis was experimentally tested in primary human osteoblasts (HOB).

\section{Materials and methods}

Primary $\mathrm{HOB}$ growing and testing. Proliferating HOB were purchased from PromoCell (Heidelberg, Germany). The donor was a healthy 60-year-old Caucasian female. The cells were grown in phenol red-free cell growth medium (PromoCell) at $37^{\circ} \mathrm{C}$ and $5 \% \mathrm{CO}_{2}\left(\mathrm{CO}_{2}\right.$-incubator; Sanyo, Moriguchi, Japan). Trypsinization was performed following the PromoCell's subcultivation instructions. The experiment started with HOB in their 5th passage. After 24 and 48 h of HOB exposure to different concentrations of $17-\beta$-estradiol $(1,10$ and $100 \mathrm{nM})$, to specific CB-2 agonist (R,S)-AM1241 (1.0 and $7.5 \mu \mathrm{M})$, to specific CB-2 antagonist/inverse agonist AM630 $(10 \mu \mathrm{M})$ and to their selected combinations, the colorimetric cell viability test WST- 8 (PromoKine, Milpitas, CA, USA; cat. no. PK-CA705-CK04-100) and alkaline phosphatase activity colorimetric assay (BioVision, Milpitas, CA, USA; cat. no. K412-500) were performed in triplicates, strictly following the manufacturer's instructions. (R,S)-AM1241 (cat. no. A6478-5MG), AM630 (cat. no. SML0327-5MG) and $17-\beta$-estradiol (cat. no. E2758-1G) were all obtained from Sigma (St. Louis, MO, USA). The samples with HOB exposed to $1 \mathrm{nM}$ concentration of $17-\beta$-estradiol, which approximately corresponds to physiological estrogen levels in healthy females (25), were treated as controls.

Statistical analysis. All the data are presented as means \pm standard deviation from three experimental samples. Statistical differences between the groups were determined using SPSS version 18.0 software (SPSS, Inc., Chicago, IL, USA), with independent samples t-test. $\mathrm{P}<0.05$ was considered to indicate a statistically significant difference.

\section{Results}

Proliferation activity. In detail, the results on HOB proliferation activity are presented in Figs. 1-3.

Influence of a combination of 17- $\beta$-estradiol and specific $C B-2$ antagonist/inverse agonist on $\mathrm{HOB}$ proliferation activity.
After $24 \mathrm{~h}$, the highest proliferation activity was observed in HOB exposed to the specific CB-2 agonist (7.5 $\mu \mathrm{M}$; Fig. 3), $100 \mathrm{nM}$ concentration of $17-\beta$ estradiol and in HOB exposed to a combination of $10 \mathrm{nM}$ concentration of $17-\beta$ estradiol with $10 \mu \mathrm{M}$ of the specific CB-2 antagonist/inverse agonist. The interaction between $17-\beta$-estradiol and specific CB-2 antagonist/inverse agonist on $\mathrm{HOB}$ proliferation activity thus appears to be synergistic.

Influence of 17- $\beta$-estradiol on $\mathrm{HOB}$ proliferation activity. The influence of 17- $\beta$-estradiol (1, 10 and $100 \mathrm{nM})$ on HOB proliferation activity was dose-dependent; HOB proliferation activity increased with increasing $17-\beta$-estradiol concentrations (Figs. 1 and 2).

Influence of specific $C B-2$ agonist on $\mathrm{HOB}$ proliferation activity. Similar dose-dependent findings were observed in HOB treated with specific CB-2 agonist; higher concentration of specific CB-2 agonist $(7.5 \mu \mathrm{M})$ resulted in increased $\mathrm{HOB}$ proliferation activity compared to the lower concentration of the specific CB-2 agonist (1 $\mu \mathrm{M})$ (Fig. 3).

Influence of a combination of 17- $\beta$-estradiol and specific $C B-2$ agonist on $\mathrm{HOB}$ proliferation activity. $\mathrm{HOB}$ exposed only to specific CB-2 agonist ( $7.5 \mu \mathrm{M})$ had higher proliferation activity compared to $\mathrm{HOB}$ exposed to a combination of specific CB-2 agonist $(7.5 \mu \mathrm{M})$ and $17-\beta$-estradiol $(10 \mathrm{nM})$ (Figs. 1 and 3$)$. HOB proliferation activity of the combination was similar to that found in HOB treated only with $10 \mathrm{nM} 17-\beta$-estradiol. The interaction between $17-\beta$-estradiol and specific CB-2 agonist on $\mathrm{HOB}$ proliferation activity thus appears to be antagonistic.

Influence of specific $C B-2$ on $\mathrm{HOB}$ proliferation activity. Specific CB-2 agonist at $7.5 \mu \mathrm{M}$ increased $\mathrm{HOB}$ proliferation activity more than specific CB-2 antagonist/inverse agonist at $10 \mu \mathrm{M}$. These results also show that HOB proliferation activity was higher when the cells were concomitantly treated with a combination of specific CB-2 agonist $(7.5 \mu \mathrm{M})$ and specific CB-2 antagonist/inverse agonist $(10 \mu \mathrm{M})$ compared to cell exposure solely to specific CB-2 antagonist/inverse agonist $(10 \mu \mathrm{M})$.

Similar findings on HOB proliferation activity were also observed after $48 \mathrm{~h}$ of incubation; however, the differences after $48 \mathrm{~h}$ were less prominent. In all the experiments, HOB successfully passed the alkaline phosphatase differentiation test.

\section{Discussion}

To the best of our knowledge, the present study shows for the first time, a probable synergistic interaction between $17-\beta$-estradiol and the specific CB-2 antagonist/inverse agonist AM630, as observed in primary $\mathrm{HOB}$ in vitro.

The influence of a combination of $17-\beta$-estradiol and specific CB-2 antagonist/inverse agonist on HOB proliferation activity was examined. The results highlighted that the combination of $17-\beta$-estradiol $(10 \mathrm{nM})$ with specific CB-2 antagonist/inverse agonist $(10 \mu \mathrm{M})$ increases HOB proliferation activity $\sim 32 \%$ compared to proliferation activity of HOB exposed solely to the same concentration of $17-\beta$-estradiol $(10 \mathrm{nM})$. To achieve 


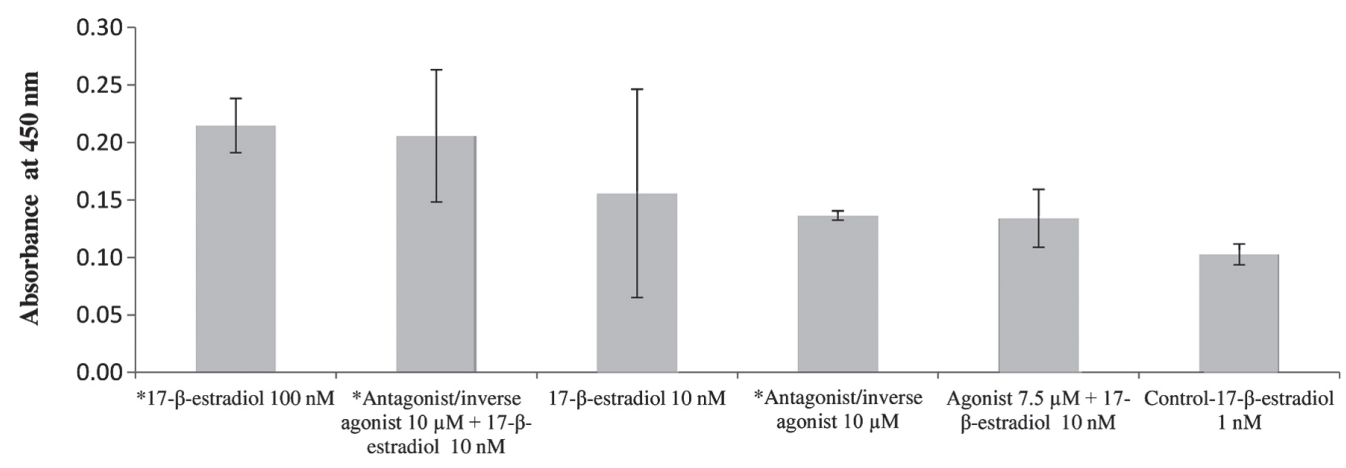

Figure 1. Human osteoblast (HOB) proliferation activity after $24 \mathrm{~h}$ of exposure. Average absorbance values of triplicates (which are in linear correlation with HOB proliferation activity) and standard deviations after $24 \mathrm{~h}$ of exposure are shown. "Statistically significant differences $(\mathrm{P}<0.05)$. ${ }^{*} \mathrm{P}<0.05$, compared to the control (1 nM 17-B-estradiol).

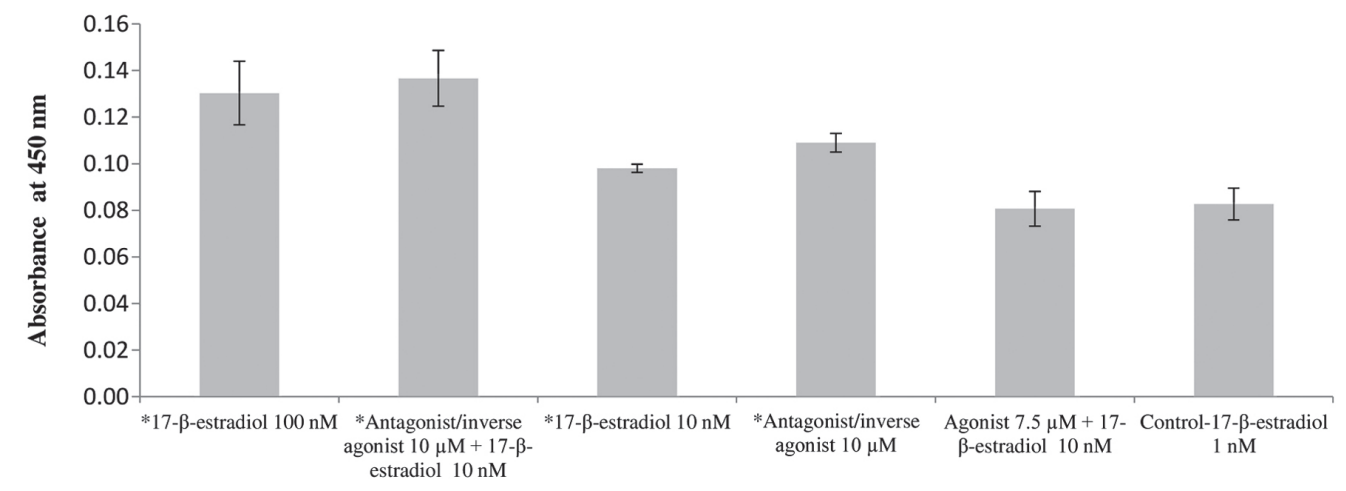

Figure 2. Human osteoblast (HOB) proliferation activity after $48 \mathrm{~h}$ of exposure. Average absorbance values of triplicates (which are in linear correlation with HOB proliferation activity) and standard deviations after $48 \mathrm{~h}$ of exposure are shown. ${ }^{*}$ Statistically significant differences $(\mathrm{P}<0.05)$. ${ }^{*} \mathrm{P}<0.05$, compared to the control (1 nM 17-B-estradiol).

almost the same effect on HOB proliferation activity as with $100 \mathrm{nM} 17-\beta$-estradiol, 10-times lower concentrations of $17-\beta$-estradiol $(10 \mathrm{nM})$ could be used when co-administering $17-\beta$-estradiol with specific CB-2 antagonist/inverse agonist $(10 \mu \mathrm{M})$. A synergistic interaction between estrogens and specific CB-2 antagonists/inverse agonists could be proposed and explained by the possibility of the increase in CB-2 receptor expression influenced by estrogens and/or by interactions on other molecular levels. 17- $\beta$-Estradiol could be assumed to increase the expression of CB-2 receptors, as has been previously observed in osteoclasts in vitro (24), or it is possible that estrogens act through other, non-genomic mechanisms (26). Recent studies also show that selective estrogen modulators, raloxifene (27), bazedoxifene and lasofoxifene, behave as CB-2 inverse agonists (28), which may also be true for $17-\beta$-estradiol and would correlate with the present results.

Previous studies showed that CB-2 receptor antagonist/inverse agonist AM630 inhibited osteoclast formation and bone resorption in vitro $(12,29)$. Furthermore, it has been shown that the administration of AM630 to ovariectomized wild-type mice prevented ovariectomy-induced bone loss (29). The present results do not entirely support the above findings; HOB proliferation activity after $24 \mathrm{~h}$ was higher compared to control cells when the tested cells were exposed to specific CB-2 antagonist/inverse agonist as the only testing substance.

Influence of $17-\beta$-estradiol on HOB proliferation activity. Estrogens have antiresorptive properties and have been in

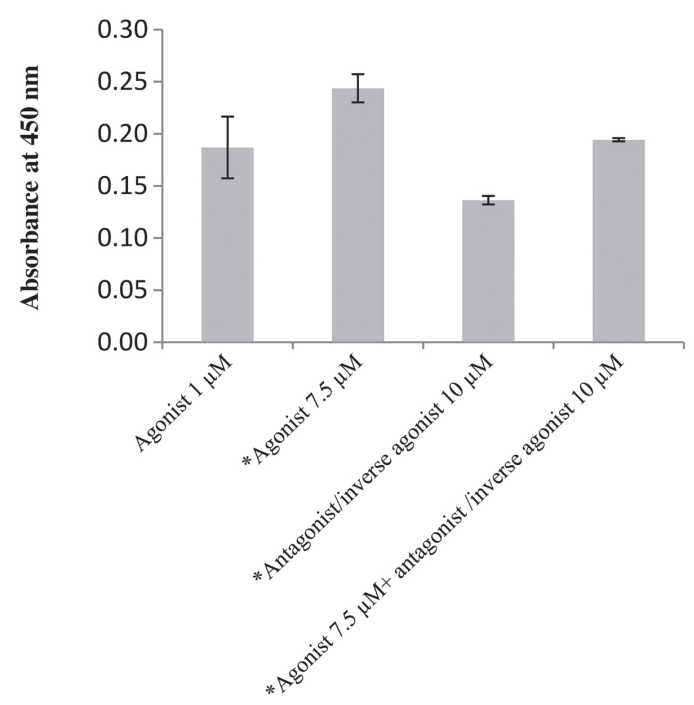

Figure 3. Human osteoblast (HOB) proliferation activity after $24 \mathrm{~h}$ of exposure. Average absorbance values of triplicates exposed to cannabinoid receptor 2 antagonist/inverse agonist or agonist (which are in linear correlation with HOB proliferation activity) and standard deviations after $24 \mathrm{~h}$ of exposure are shown. "Statistically significant differences $(\mathrm{P}<0.05)$. ${ }^{*} \mathrm{P}<0.05$, compared to the control (1 nM 17-B-estradiol).

clinical use for treatment of osteoporosis for a long time (30). The results from the present study confirm a dose-dependent estrogen response on HOB proliferation activity. As expected, 
higher concentrations of $17-\beta$-estradiol resulted in higher HOB proliferation activity compared to lower $17-\beta$ estradiol concentrations.

The influence of specific CB-2 agonist on HOB proliferation activity was investigated in the present study. Previous studies have shown that specific CB-2 agonists directly stimulate stromal cells/osteoblasts and simultaneously inhibit monocyte/osteoclasts, directly and indirectly by inhibiting the expression of RANKL in stromal cells/osteoblasts (13). Previous studies have also shown that specific CB-2 agonists induce mitogenic effects in osteoblasts via activation of a Gi protein-cyclin D1 and the extracellular signal-regulated kinase $1 / 2$ pathway $(31,32)$. This was indirectly confirmed in the present study by the increase in proliferation activity of HOB when they were treated solely with the specific CB-2 agonist. As hypothesized, HOB proliferation activity was influenced by the specific CB-2 agonist in a dose-dependent manner; higher concentrations of the specific CB-2 agonist increased HOB proliferation activity more than the lower concentrations.

The influence of a combination of $17-\beta$-estradiol and specific CB-2 agonist were examined on HOB proliferation activity. The results show that in the absence of $17-\beta$-estradiol, the specific CB-2 agonist had a stimulating effect on HOB proliferation activity in vitro, whereas the combination of the two substances appeared to have an antagonistic effect on HOB proliferation activity. This result additionally confirms the interplay between estrogens and cannabinoids, as already proposed by a synergistic interaction between $17-\beta$-estradiol and specific CB-2 antagonist/inverse agonist.

Additional notable observations in the present study are that $7.5 \mu \mathrm{M}$ specific $\mathrm{CB}-2$ agonist increases $\mathrm{HOB}$ proliferation activity to a higher extent compared to $10 \mathrm{nM}$ specific CB-2 antagonist/inverse agonist. Furthermore, in the presence of $7.5 \mu \mathrm{M}$ specific $\mathrm{CB}-2$ agonist and $10 \mathrm{nM}$ specific $\mathrm{CB}-2$ antagonist/inverse agonist, HOB proliferation activity is higher compared to cells treated with $10 \mathrm{nM}$ specific CB-2 antagonist/inverse agonist as the only testing substance. Therefore, it could be speculated that in the absence of estrogens, specific CB-2 agonists may overcome the effects of specific CB-2 antagonists/inverse agonists on HOB proliferation activity. However, further studies with different CB-2 agonists and antagonists/inverse agonists in various concentrations should be tested to clarify the above observations and to evaluate their potential clinical importance.

Another factor in the present study is that all the experiments and treatments, dose- and time-dependency, as well as the controls, showed that HOB in cell cultures maintained their alkaline phosphatase activity. In brief, HOB in vitro did not de-differentiate in the controls or when treated with various chemicals, but further quantitative studies should be performed in order to evaluate the degree of differentiation exactly in each single experiment setting.

There are possible clinical applications for the results of the present study. The difference between the actions of cannabinoid antagonists/agonists in the presence or absence of estrogens may lead to specific drug treatment of osteoporosis in elderly patients with specific CB-2 agonists, which are more effective in the presence of low estrogen concentrations and even better as a combination drug for females with
CB-2 antagonists/inverse agonists and 17- $\beta$-estradiol, which would have a synergistic effect on osteoblasts activity and could provide novel treatment of postmenopausal induced osteoporosis in females. This could lead to a new, possibly gender-dependent strategy in osteoporosis prevention. Firstly, combination treatment of specific CB-2 antagonists/inverse agonists and estrogens may lead to lower doses of estrogens administered to patients with osteoporosis and consequently fewer of their harmful side-effects and minimizing of the serious complications. Notably, it is well-known that long-term use of estrogens can promote carcinogenesis, particularly in breast and endometrial cancer (32-34). Secondly, a number of studies indicate that the endocannabinoid system plays protective roles against the growth and the spreading of several types of carcinomas, including endometrial and breast cancers $(35,36)$. Therefore, a combination of cannabinoids and estrogens may have beneficial effects by inhibiting estrogen-induced carcinogenesis. Thirdly, adding specific CB-2 antagonists/inverse agonists to contraceptive pills could increase maximal bone mineral density in females. Contraceptive pills are most commonly used before the age of 30 years, which corresponds to the phase of rapid skeletal growth and increasing bone mineral density; this makes it ideal for preventing osteoporosis or delaying its development. Furthermore, the involvement of the endocannaboid system is also indicated in cardioprotection (37), which is a particularly important concern in the postmenopausal era. These benefits could potentially be increased by synergistic interactions with estrogens.

Recent pharmacological improvements allow oral application of specific CB-2 agonists (i.e., S-777469) and specific CB-2 antagonists/inverse agonists (i.e., SR 144528); therefore $(38,39)$, their potential medical applications in the treatment of various diseases are becoming even more noteworthy. By contrast, safety and adverse effects of CB-2 agonists/antagonists/inverse agonists should be examined prior to clinical use.

In conclusion, the results of the present study are quite informative and represent the idea of a probable synergistic interaction between $17-\beta$-estradiol and specific CB-2 antagonist/inverse agonist in primary HOB. However, these observations require further investigation in order to clarify and evaluate the clinical applicability of the results. Mineralization, specific osteoblast molecular biomarkers (i.e., runt-related transcription factor 2, osteonectin, osteocalcin, bone sialoprotein and collagen I), molecular pharmacodynamic interactions, expression of ERs $\alpha$ and $\beta$, as well as the CB-1 and -2 receptors expression should be performed. As indicated in the introduction, other receptors are also involved in cannabinoid signaling pathways. For this reason, an in depth understanding of how TRPV1 and GPR55 receptors in combination with CB-1 and -2 receptors interact to modify the activity of osteoblasts could be helpful in predicting the efficiency of cannabinoid pharmacotherapy.

\section{Acknowledgements}

The authors would like to thank Mr. Alojz Tapajner for his useful suggestions in interpreting the study results and Mr. Samo Lorber for helping to prepare the figures. 


\section{References}

1. Raisz LG: Pathogenesis of osteoporosis: concepts, conflicts, and prospects. J Clin Invest 115: 3318-3325, 2005.

2. Reginster JY and Burlet N: Osteoporosis: a still increasing prevalence. Bone 38 (Suppl 1): S4-S9, 2006.

3. Centrella M and McCarthy TL: Estrogen receptor dependent gene expression by osteoblasts - direct, indirect, circumspect, and speculative effects. Steroids 77: 174-184, 2012.

4. Bilezikian JP, Raisz LG and Martin TJ: Principles of bone biology. In: Estrogens and Progestins. Turner RT, Rickard DJ, Iwaniec UT and Spelsberg TC (eds). 3rd edition. Elsevier, Amsterdam, pp855-885, 2008.

5. Bradford PG, Gerace KV, Roland RL and Chrzan BG: Estrogen regulation of apoptosis in osteoblasts. Physiol Behav 99: 181-185, 2010.

6. Howlett AC: The cannabinoid receptors. Prostaglandins Other Lipid Mediat 68-69: 619-631, 2002.

7. Whyte LS, Ryberg E, Sims NA, Ridge SA, Mackie K, Greasley PJ, Ross RA and Rogers MJ: The putative cannabinoid receptor GPR55 affects osteoclast function in vitro and bone mass in vivo. Proc Natl Acad Sci USA 106: 16511-16516, 2009.

8. van der Stelt M, Trevisani M, Vellani V, De Petrocellis L, Schiano Moriello A, Campi B, McNaughton P, et al: Anandamide acts as an intracellular messenger amplifying $\mathrm{Ca}^{2+}$ influx via TRPV1 channels. EMBO J 24: 3026-3037, 2005.

9. Julien B, Grenard P, Teixeira-Clerc F, Van Nhieu JT, Li L, Karsak M, Zimmer A, Mallat A and Lotersztajn S: Antifibrogenic role of the cannabinoid receptor $\mathrm{CB} 2$ in the liver. Gastroenterology 128: 742-755, 2005

10. Steffens S, Veillard NR, Arnaud C, Pelli G, Burger F, Staub C, Karsak M, Zimmer A, Frossard JL and Mach F: Low dose oral cannabinoid therapy reduces progression of atherosclerosis in mice. Nature 434: 782-786, 2005.

11. Wright K, Rooney N, Feeney M, Tate J, Robertson D, Welham M and Ward S: Differential expression of cannabinoid receptors in the human colon: cannabinoids promote epithelial wound healing. Gastroenterology 129: 437-453, 2005.

12. Idris AI, van 't Hof RJ, Greig IR, Ridge SA, Baker D, Ross RA and Ralston SH: Regulation of bone mass, bone loss and osteoclast activity by cannabinoid receptors. Nat Med 11: 774-779, 2005

13. Ofek O, Karsak M, Leclerc N, Fogel M, Frenkel B, Wright K Tam J, Attar-Namdar M, Kram V, Shohami E, et al: Peripheral cannabinoid receptor, CB2, regulates bone mass. Proc Natl Acad Sci USA 103: 696-701, 2006

14. Whyte LS, Ford L, Ridge SA, Cameron GA, Rogers MJ and Ross RA: Cannabinoids and bone: endocannabinoids modulate human osteoclast function in vitro. Br J Pharmacol 165 2584-2597, 2012

15. Hanus L, Breuer A, Tchilibon S, Shiloah S, Goldenberg D, Horowitz M, Pertwee RG, Ross RA, Mechoulam R and Fride E: HU-308: a specific agonist for $\mathrm{CB}_{2}$, a peripheral cannabinoid receptor. Proc Natl Acad Sci USA 96: 14228-14233, 1999.

16. Wartmann M, Campbell D, Subramanian A, Burstein SH and Davis RJ: The MAP kinase signal transduction pathway is activated by the endogenous cannabinoid anandamide. FEBS Lett 359: 133-136, 1995.

17. Melck D, Rueda D, Galve-Roperh I, De Petrocellis L, Guzman M and Di Marzo V: Involvement of the cAMP/protein kinase A pathway and of mitogen-activated protein kinase in the anti-proliferative effects of anandamide in human breast cancer cells. FEBS Lett 463: 235-240, 1999.

18. Liu J, Gao B, Mirshahi F, Sanyal AJ, Khanolkar AD, Makriyannis A and Kunos G: Functional CB1 cannabinoid receptors in human vascular endothelial cells. Biochem J 346: 835-840, 2000

19. Derkinderen P, Ledent C, Parmentier M and Girault JA: Cannabinoids activate $\mathrm{p} 38$ mitogen-activated protein kinases through CB1 receptors in hippocampus. J Neurochem 77: 957-960, 2001

20. Rueda D, Galve-Roperh I, Haro A and Guzmán M: The $\mathrm{CB}_{1}$ cannabinoid receptor is coupled to the activation of c-Jun N-terminal kinase. Mol Pharmacol 58: 814-820, 2000.

21. Mombouli JV, Schaeffer G, Holzmann S, Kostner GM and Graier WF: Anandamide-induced mobilization of cytosolic $\mathrm{Ca}^{2+}$ in endothelial cells. Br J Pharmacol 126: 1593-1600, 1999.
22. Rossi F, Siniscalco D, Luongo L, De Petrocellis L, Bellini G, Petrosino S, Torella M, Santoro C, Nobili B, Perrotta S, et al: The endovanilloid/endocannabinoid system in human osteoclasts: possible involvement in bone formation and resorption. Bone 44: 476-484, 2009.

23. Rossi F, Bellini G, Luongo L, Torella M, Mancusi S, De Petrocellis L, Petrosino S, Siniscalco D, Orlando P, Scafuro M, et al: The endovanilloid/endocannabinoid system: a new potential target for osteoporosis therapy. Bone 48: 997-1007, 2011.

24. Rossi F, Bellini G, Luongo L, Mancusi S, Torella M, Tortora C, Manzo I, Guida F, Nobili B, de Novellis V and Maione S: The 17-beta-oestradiol inhibits osteoclast activity by increasing the cannabinoid CB2 receptor expression. Pharmacol Res 68: 7-15, 2013.

25. Liu SF, Wang ZX, Yuan YE, Bing SM, Zhang BZ, Wu JZ, Wu YE and Peng XY: Hormone changes during the menstrual cycle of Chinese women. J Reprod Fertil 76: 43-52, 1986

26. Kousteni S, Chen JR, Bellido T, Han L, Ali AA, O'Brien CA, Plotkin L, Fu Q, Mancino AT, Wen Y, et al: Reversal of bone loss in mice by nongenotropic signaling of sex steroids. Science 298 : 843-846, 2002.

27. Kumar $\mathrm{P}$ and Song $\mathrm{ZH}$ : Identification of raloxifene as a novel CB2 inverse agonist. Biochem Biophys Res Commun 435: 76-81, 2013.

28. Kumar P and Song ZH: CB2 cannabinoid receptor is a novel target for third-generation selective estrogen receptor modulators bazedoxifene and lasofoxifene. Biochem Biophys Res Commun 443: 144-149, 2014.

29. Idris AI, Sophocleous A, Landao-Bassonga E, van't Hof RJ and Ralston SH: Regulation of bone mass, osteoclast function, and ovariectomy-induced bone loss by the type 2 cannabinoid receptor. Endocrinology 149: 5619-5626, 2008.

30. Horst-Sikorska W and Wawrzyniak A: The role of hormonal therapy in osteoporosis. Endokrynol Pol 62: 61-64, 2011.

31. Ofek O, Attar-Namdar M, Kram V, Dvir-Ginzberg M, Mechoulam R, Zimmer A, Frenkel B, Shohami E and Bab I: CB2 cannabinoid receptor targets mitogenic Gi protein-cyclin D1 axis in osteoblasts. J Bone Miner Res 26: 308-316, 2011.

32. Sophocleous A, Landao-Bassonga E, Van't Hof RJ, Idris AI and Ralston SH: The type 2 cannabinoid receptor regulates bone mass and ovariectomy-induced bone loss by affecting osteoblast differentiation and bone formation. Endocrinology 152: 2141-2149, 2011.

33. Chlebowski RT, Anderson GL, Gass M, Lane DS, Aragaki AK, Kuller LH, Manson JE, Stefanick ML, Ockene J, Sarto GE, et al: Estrogen plus progestin and breast cancer incidence and mortality in postmenopausal women. JAMA 304: 1684-1692, 2010.

34. Lépine J, Audet-Walsh E, Grégoire J, Têtu B, Plante M, Ménard V, Ayotte P, Brisson J, Caron P, Villeneuve L, et al: Circulating estrogens in endometrial cancer cases and their relationship with tissular expression of key estrogen biosynthesis and metabolic pathways. J Clin Endocrinol Metab 95: 2689-2698, 2010

35. Guida M, Ligresti A, De Filippis D, D'Amico A, Petrosino S, Cipriano M, Bifulco G, Simonetti S, Orlando P, Insabato L, et al: The levels of the endocannabinoid receptor CB2 and its ligand 2-arachidonoylglycerol are elevated in endometrial carcinoma. Endocrinology 151: 921-928, 2010.

36. Qamri Z, Preet A, Nasser MW, Bass CE, Leone G, Barsky SH and Ganju RK: Synthetic cannabinoid receptor agonists inhibit tumor growth and metastasis of breast cancer. Mol Cancer Ther 8: 3117-3129, 2009

37. Lagneux C and Lamontagne D: Involvement of cannabinoids in the cardioprotection induced by lipopolysaccharide. $\mathrm{Br}$ J Pharmacol 132: 793-796, 2001.

38. Odan M, Ishizuka N, Hiramatsu Y, Inagaki M, Hashizume H, Fujii Y, Mitsumori S, Morioka Y, Soga M, Deguchi M, et al: Discovery of S-777469: an orally available CB2 agonist as an antipruritic agent. Bioorg Med Chem Lett 22: 2803-2806, 2012.

39. Rinaldi-Carmona M, Barth F, Millan J, Derocq JM, Casellas P, Congy C, Oustric D, Sarran M, Bouaboula M, Calandra B, et al: SR 144528, the first potent and selective antagonist of the CB2 cannabinoid receptor. J Pharmacol Exp Ther 284: 644-650, 1998. 